\title{
Aprendizagem Ativa na Disciplina Energia, Meio Ambiente e Sustentabilidade do Primeiro Ano da Engenharia Elétrica da Poli-USP
}

\author{
José Aquiles Baesso Grimoni*, Luciana Guidon Coelho \\ 1Departamento de Engenharia de Energia e Automação Elétricas da Escola Politécnica \\ da Universidade de São Paulo
}

* Autor para correspondência: aquiles@pea.usp.br

\begin{abstract}
RESUMO
Este relato tem o intuito de apresentar a proposta e os resultados de um trabalho solicitado aos alunos de graduação de Engenharia Elétrica da Escola Politécnica da USP, na disciplina Energia, Meio Ambiente e Sustentabilidade. O trabalho solicitado é uma estratégia de aprendizagem ativa, na qual os alunos devem estar ativamente envolvidos na solução de problemas reais ou situações da vida profissional. Como uma tentativa de avaliar a aprendizagem, a opinião e as reflexões dos alunos durante a realização da atividade, um questionário foi respondido por eles. A conclusão deste artigo é que a disciplina está, aparentemente, no caminho certo, promovendo aprendizagem e reflexão e ainda apresentando aos alunos uma breve introdução sobre geração e uso de energia.
\end{abstract}

Palavras-chave: Aprendizagem Ativa; Graduação; Engenharia Elétrica.

\begin{abstract}
This report is intended to present the idea and the results obtained in the assignment/project asked to the undergraduate students to do in Energy, Environment and Sustainability course of the Electrical Engineering program of the Polytechnic School of USP (University of São Paulo). This project is a strategy of active learning, in which students are actively involved in addressing and solving real problems or situations of professional life. As an attempt to assess learning, opinion and on reflexion of the students during the assignment production, a survey was answered by the students. The conclusion of this article is this course is in the "right way" to promote learning, reflexion and to present students a brief summary of energy generation and its use.
\end{abstract}

Keywords: Active Learning; Undergraduate; Electrical Engineering.

Este trabalho tem o intuito de apresentar uma estratégia de aprendizagem ativa inserida na disciplina de graduação Energia, Meio Ambiente e Sustentabilidade, da Engenharia Elétrica da Escola Politécnica da USP, e também mostrar qual foi a percepção dos alunos sobre tal estratégia utilizando dados obtidos por meio de um questionário.

É interessante observar que a estratégia de aprendizagem ativa em questão foi aplicada em uma disciplina dos primeiros anos do curso, o que pode ser muito positivo, visto que, com os alunos mais envolvidos e motivados, é possível se prever que haverá menos evasão (comum nos primeiros anos de cursos de engenharia) e que os alunos tenderão a se empenhar mais no curso (LODER et al., 2014).

A estratégia de aprendizagem ativa proposta é um trabalho a ser realizado pelos alunos ao longo da disciplina. Este trabalho tem a intenção de mobilizar os alunos, fazer com que busquem respostas e soluções, o que exige um maior envolvimento deles. Além disso, o trabalho tem o importante papel de promover a conscientização e a reflexão dos alunos, e muito provavelmente de suas famílias, para questões como eficientização energética, emissão de gases poluentes e de efeito estufa na atmosfera, preservação do meio ambiente e aspectos econômicos e políticos envolvidos em tais questões. 
É interessante que desde o início do curso de Engenharia Elétrica os alunos já tenham essa visão ampla do impacto de sua futura profissão no mundo.

\section{A Disciplina Energia, Meio Ambiente e Sustentabilidade}

Trata-se de uma disciplina de graduação, do departamento de Engenharia de Energia e Automação Elétricas. Na estrutura curricular vigente até 2013, era uma disciplina oferecida para o segundo ano de Engenharia Elétrica (com a sigla PEA2200), mas a partir de 2014, com a nova estrutura curricular, a disciplina é oferecida para os alunos do primeiro ano do curso de Engenharia Elétrica (com a sigla PEA3100). A disciplina oferece quatro créditos e equivale a uma carga horária total de sessenta horas, distribuída em duas aulas de cem minutos por semana.

O objetivo da disciplina é permitir aos alunos conhecerem os conceitos fundamentais sobre a energia, em especial sobre a energia elétrica, e suas relações com o meio ambiente e o desenvolvimento sustentável, abrangendo os aspectos técnicos, socioeconômicos e político-ambientais.

A disciplina é composta de aulas expositivas, provas, exercícios, uma visita (obrigatória) aos Sistemas Fotovoltaicos do Instituto de Energia e Ambiente da USP (IEE) e um trabalho que envolve aprendizagem ativa, que será realizado em grupo, ao longo de toda a disciplina, e contempla apresentações e entrega de relatórios individuais e consolidados. Para os alunos que estão cursando a disciplina no segundo ano (PEA2200), também há uma palestra (obrigatória) sobre sistemas eólicos.

\section{Aprendizagem Ativa na Disciplina Energia, Meio Ambiente e Sustentabilidade}

$\mathrm{O}$ intuito da introdução de estratégia de aprendizagem ativa na disciplina é, desde o início do curso de Engenharia, aproximar o aluno da realidade e das experiências do mercado de trabalho, além de fazê-lo participar e não ser apenas um mero espectador na sala de aula. $\mathrm{O}$ processo de aprendizado dos alunos utilizando tais estratégias é mais eficiente, visto que eles se envolvem com atividades associadas ao conteúdo da disciplina, em situações práticas e reais, sendo muitas delas situações com que se depararão em seu cotidiano.

A estratégia que se buscou inserir na disciplina é a de aprendizagem orientada a projetos, estratégia pedagógica na qual os grupos de estudantes estão ativamente envolvidos em abordar ou resolver problemas ou situações reais da vida profissional. A vantagem dessa abordagem é que eles aprendem a interagir uns com os outros e com a comunidade em torno deles, adquirem conhecimento, desenvolvem habilidades, atitudes e comportamentos que lhes permitem lidar melhor em um cenário de trabalho após a conclusão de seus estudos (VILLAS-BOAS et al., 2012).

Em suma, no contexto do Ensino Superior, a aprendizagem ativa envolve os alunos na elaboração de atividades e os faz pensar no que estão fazendo. Os alunos se engajam nas atividades propostas, são motivados e devem desenvolver as capacidades de análise, síntese e avaliação (BONWELL, 2000).

No trabalho da disciplina, os alunos devem fazer um diagnóstico energético de sua residência, analisar os dados e então propor substituições, mudanças de hábitos de consumo de energia e troca de energéticos, sempre levando em consideração a eficiência energética, os custos envolvidos e os impactos ambientais, procedimento análogo a uma consultoria, uma situação que poderia ser real na vida profissional.

O trabalho também tem o intuito de gerar reflexão e conscientização nos alunos para as questões ambientais envolvidas na Engenharia Elétrica.

\section{O Trabalho: Diagnóstico Energético, Eficiência Energética, Substituições Interenergéticas e Correlação entre Energia, Desenvolvimento e Meio Ambiente}

O objetivo do trabalho é que os alunos façam uma avaliação sobre a caracterização das necessidades energéticas dos moradores de uma residência (escolhida por cada um dos alunos), sobre as possibilidades de ações que permitam reduzir esse consumo, sem afetar a qualidade do serviço energético, e as possibilidades de geração própria ou substituição de energéticos. Além disso, espera-se que os alunos façam a avaliação dos impactos técnicos, econômicos 
e socioambientais de todas as análises e ações visando à sustentabilidade.

Também são definidos como objetivos principais:

1. Permitir ao aluno avaliar o consumo energético de sua residência;

2. Desenvolver no aluno noções sobre eficiência energética;

3. Possibilitar que o aluno tenha noções sobre substituição de energéticos e autoprodução de energia e

4. Desenvolver no aluno noções sobre viabilidade técnico-econômica e a correlação entre energia, meio ambiente e desenvolvimento.

O trabalho da disciplina foi dividido em cinco fases, sendo que cada nova etapa só é explicada e solicitada aos alunos (em conjunto com os conteúdos técnicos que dão suporte à atividade) após o término e a apresentação da etapa anterior.

A cada etapa os alunos deverão entregar um relatório individual, referente ao levantamento e aos estudos feitos na própria residência, um relatório consolidado, contendo as comparações e comentários sobre as diferenças e similaridades encontradas nos estudos individuais, e também deverá ser feita uma apresentação para a classe por dois grupos dos dez de cada turma de cerca de sessenta alunos.

\section{Etapa 1: Usos Finais de Energia}

Nesta etapa, os alunos devem realizar um levantamento do consumo mensal dos diversos energéticos (como energia elétrica, gás natural, etanol e gasolina) consumidos durante os últimos doze meses, ou seja, fazer o levantamento da quantidade consumida de cada energético, dos hábitos de consumo (intensidade, período e tempo de uso), bem como determinar a participação percentual e absoluta de cada energético (montagem da matriz energética).

Para a realização desta etapa, os alunos devem consultar dados de placa de equipamentos em casa, manuais de fabricantes, levantar os hábitos de consumo dos moradores e, assim, aplicar a teoria aprendida em sala de aula para a organização e a análise desses dados, a conversão de unidades e a elaboração de gráficos e tabelas.

Os alunos devem apresentar, por exemplo, o cálculo do consumo mensal de energia para cada um dos energéticos, cálculo do consumo mensal por uso final de energia, o gráfico de barras dos consumos totais mensais de energia dos últimos doze meses e o gráfico da curva diária de carga para verão, inverno, dia típico de semana e dia típico de final de semana. Alguns indicadores importantes para comparação entre as residências também devem ser determinados pelos alunos, como consumo de energia per capita, energia por área residencial e fator de carga.

\section{Etapa 2: Conservação de Energia}

Nesta etapa, os alunos realizam um levantamento do potencial de economia de energia na residência, fazem uma análise para verificar a viabilidade econômica da adoção das alternativas utilizando os indicadores determinados pelos professores e, para cada uso final, identificam ou sugerem ações que possam ser tomadas no sentido de tornar os usos finais mais eficientes.

Os alunos devem identificar ações que podem ser tomadas para reduzir o consumo de energia elétrica, como, por exemplo, a troca de equipamentos da residência. Em seguida, cabe-lhes fazer uma pesquisa de mercado para verificar quais equipamentos podem ser substituídos e os dados e custos desses equipamentos, e então simular quanto seria a economia após as ações.

Devem ser verificados pelos alunos a redução da conta anual de energia elétrica, o tempo (em anos) de recuperação dos investimentos (payback simples), o valor presente líquido (VPL) e o custo da energia conservada (CEE) em R $\$ / k W h$. Também apresentarão gráficos da curva de carga antes e depois das ações de eficientização energética, gráficos dos fatores de carga, entre outros.

\section{Etapa 3: Energia Solar (Coletor Solar Plano)}

Nesta etapa, os alunos devem simular a substituição da tecnologia utilizada no aquecimento de água de banho por coletor solar plano, 
sendo que, para tal, precisam realizar o cálculo do dimensionamento de um coletor solar para atendimento da energia térmica necessária para aquecimento de água de banho, efetuar o cálculo da economia de energia com a substituição da tecnologia atual pelo coletor solar plano, efetuar uma análise econômica da substituição de tecnologias, e apresentar comentários acerca das vantagens e desvantagens, limitações e sugestões sobre o uso de coletor solar plano.

Os alunos precisam calcular o consumo mensal de energia elétrica, no verão e no inverno, admitindo que nos meses de verão o coletor é autossuficiente e que nos meses de inverno o consumo de energia auxiliar é de 30\% em relação ao consumo de energia do equipamento antigo para as localidades situadas nas regiões Sudeste e Sul. Devem também apresentar a nova curva diária de carga, sendo uma típica de verão e outra de inverno, apontando o impacto na demanda máxima e média, calcular o payback simples e o custo da energia conservada, apresentar o layout simplificado da instalação, indicando as dimensões dos equipamentos e parâmetros de dimensionamento calculados, e, por fim, apresentar comentários acerca das vantagens, desvantagens, limitações e sugestões sobre o uso de coletor solar plano.

\section{Etapa 4: Energia Solar (Sistemas Fotovoltai- $\underline{\mathrm{cos})}$}

Nesta etapa, os alunos devem realizar uma avaliação técnico-econômica da implantação de um sistema fotovoltaico nas edificações (em suas casas ou apartamentos). Neste caso, a opção adotada é a de um sistema fotovoltaico conectado à rede elétrica.

Os alunos devem resgatar os dados da Etapa 2 (eficiência energética) para realizarem o dimensionamento do sistema fotovoltaico. Para tal, precisam descobrir qual é a radiação solar na residência e então calcular a energia que o painel solar deve gerar para atender ao consumo diário de carga. Em seguida, cumpre-lhes calcular a potência do painel solar e escolher os inversores. O passo seguinte é desenhar o layout e o 114 esquema de ligação dos módulos e verificar se a quantidade de painéis solares necessária cabe ou não nos telhados dos alunos. Os alunos devem apresentar desenhos e esquemas simplificados das ligações e instalações. Também é necessário fazer a avaliação econômica, pois os alunos vão pesquisar os preços dos equipamentos. Devem ser calculados o custo total do investimento, o custo do kWp (kiloWatt pico) instalado e o custo da energia gerada.

No relatório, cabe aos alunos apresentarem a potência do painel solar, a potência dos inversores, o número de módulos e inversores, o desenho esquemático da ligação, a área ocupada pelos módulos, o custo total do investimento, o custo do kWp instalado e o custo de energia gerada e as análises do estudo.

Etapa 5: Energia, Desenvolvimento e Meio Ambiente

O intuito desta etapa é verificar a pegada de carbono do consumo da residência da Etapa 1 e a redução com as ações da Etapa 2. Os alunos devem determinar a emissão de $\mathrm{CO}_{2}$ equivalente em função dos valores da matriz de consumo de energia residencial das etapas 1 e 2 , em função das ações realizadas. Devido à complexidade da modelagem e da análise, não será avaliada a emissão de $\mathrm{CO}_{2}$ do ciclo de vida completo (ACV) de cada fonte energética e combustível utilizado, mas o aluno deve ter consciência da importância dessa análise mais completa. A análise será restringida à emissão na operação. O intuito é avaliar o efeito de redução anual de emissão de $\mathrm{CO}_{2}$ da Etapa 2 em relação à Etapa 1, considerando apenas o consumo das curvas de carga levantadas pelos alunos do período de verão (dezembro a abril) e o consumo das curvas de carga do período de inverno (maio a novembro).

\section{Estudo da Aplicação do Trabalho: Efetividade e Opinião dos Alunos}

Os autores procuraram entender melhor sobre a aprendizagem dos alunos e qual a opinião deles sobre a execução do trabalho e sobre a disciplina. 
Para tal, foi elaborado um questionário on-line para ser respondido anônima e voluntariamente pelos alunos. Esse questionário foi respondido antes do término da disciplina, ou seja, o trabalho não foi totalmente finalizado pelos alunos, sendo que, ao responderem, estavam executando a Etapa 3.

O questionário está dividido de acordo com as seguintes seções: A) Seção de informações pessoais e sobre a residência analisada: perguntas sobre o perfil dos alunos (sexo, disciplina que está cursando - PEA3100 ou PEA2200 - e turma), sobre a residência analisada no trabalho (área, quantidade de moradores etc.) e sobre o perfil de consumo de energéticos da residência. Essa seção de informações é de interesse dos professores, para o conhecimento do perfil das residências que estão sendo avaliadas para o trabalho, e não será utilizada para analisar o aprendizado e as reflexões dos alunos durante o trabalho. É apenas uma seção de caracterização. B) Seção sobre a execução do trabalho: opinião dos alunos sobre o trabalho, perguntas sobre como eles sanaram as dúvidas e perguntas que buscam entender se houve aprendizado durante a execução do trabalho. G) Seção sobre as reflexões geradas em função do trabalho: perguntas sobre as reflexões feitas pelos alunos em relação aos hábitos de consumo e ações de eficientização energética. D) Seção de opinião livre: a única pergunta não obrigatória, espaço aberto para o aluno apresentar críticas, elogios e sugestões sobre o trabalho.

Os resultados considerados neste artigo foram obtidos até o dia 24 de maio de 2014, quando eram computadas 147 respostas de alunos tanto de PEA3100 como de PEA2200.

\section{Conclusões e Análise das Respostas do Questionário}

Um aspecto importante que já era de conhecimento dos professores da disciplina e que se confirmou com o questionário é a opinião dos alunos sobre o tempo dispendido para a realização do trabalho. Os alunos também reclamaram acerca do preparo de relatórios individuais sobre as residências de cada um, relatórios consolidados, além de uma apresentação em PowerPoint.

Há resultados bastante animadores para os docentes da disciplina, pois 75\% dos respondentes concordam parcial ou plenamente com a afirmação "consegui relacionar o conteúdo das aulas com as etapas de execução do trabalho", que é o intuito da disciplina: fazer com que os alunos relacionassem o que estava sendo apresentado em aula com as solicitações a cada etapa do trabalho. Já em relação ao julgamento da afirmação "tive a sensação de descobrir e/ou aprender coisas novas ao realizar o trabalho", 70\% dos respondentes selecionaram que concordam parcialmente ou plenamente, o que aponta que os objetivos do trabalho estão sendo alcançados, já que a ideia do trabalho é que os alunos aprendam coisas novas durante sua execução.

Quanto aos resultados já apresentados, ainda se pode complementar com comentários obtidos na seção D do questionário, na qual alunos afirmam que "o trabalho é divertido e, por incentivar a pesquisa por informação sobre o mecanismo de funcionamento de diversos dispositivos e a viabilidade econômica de várias medidas, teve resultados positivos em grande parcela dos colegas de minha turma" e "achei o trabalho muito interessante e, por enquanto, houve aprendizado em todas as etapas realizadas". Ou seja, há feedback positivo de alguns alunos, e o que precisa ser trabalhado é o desenvolvimento de alguma estratégia para atingir os estudantes que consideram que não houve aprendizado e que o trabalho não é interessante.

A seguir, algumas respostas, em formato de gráfico, obtidas por meio do questionário.

O questionário mostra que o trabalho atingiu um objetivo muito importante, que é conscientizar os alunos sobre a eficientização energética. $79 \%$ dos respondentes concordam que o trabalho gerou uma reflexão sobre os hábitos de consumo nas residências deles. É importante, desde o início de um curso de Engenharia Elétrica, formar profissionais conscientes e preocupados com questões de eficientização, meio ambiente e sustentabilidade; afinal, se este trabalho não for feito dentro das 


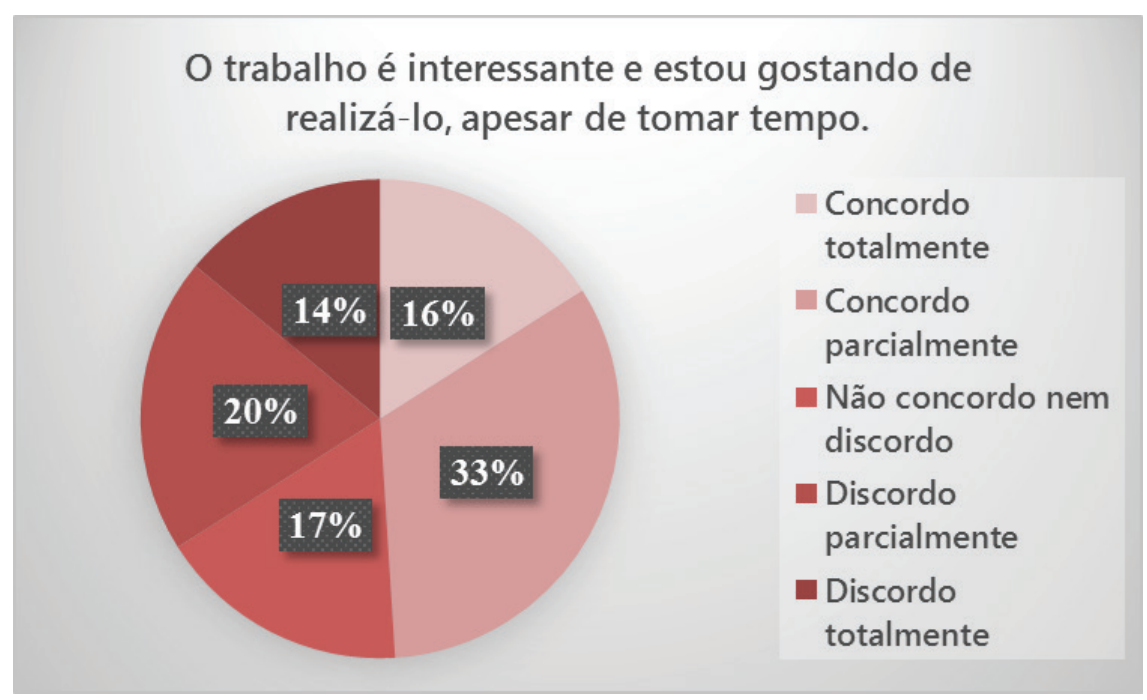

Figura 1 - A maioria dos alunos acha o trabalho interessante apesar do tempo dispendido na realização do mesmo.

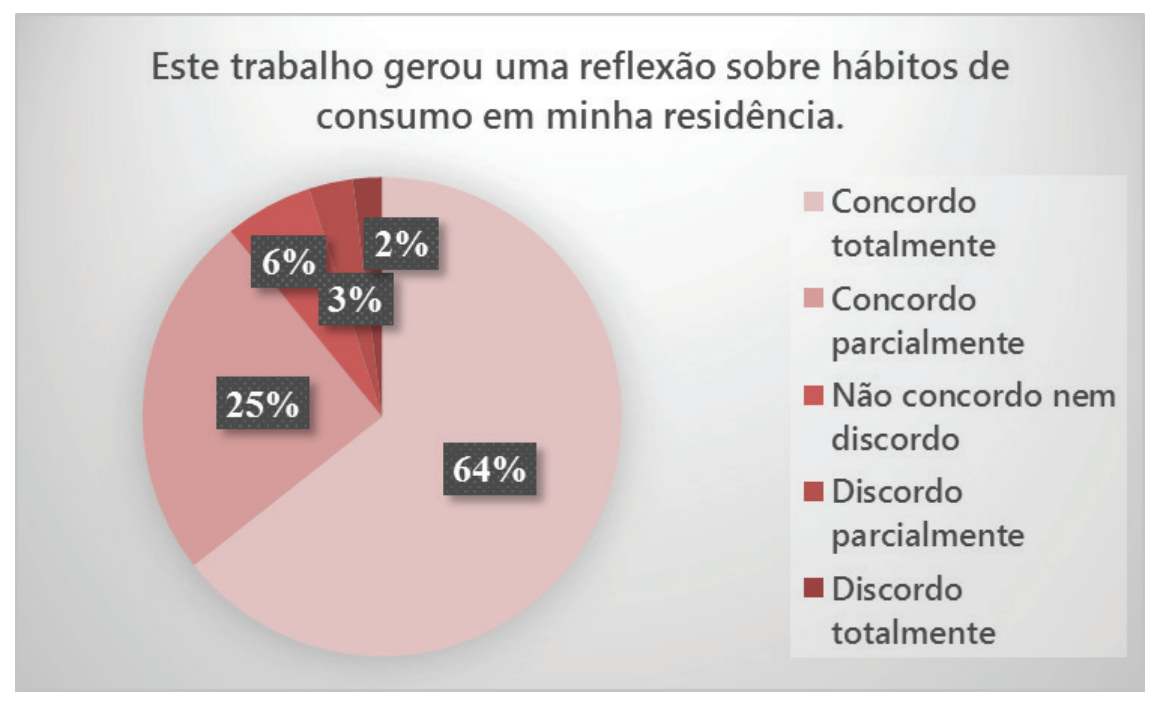

Figura 2 - O trabalho gerou reflexão sobre os hábitos de consumo dos alunos e de suas famílias.

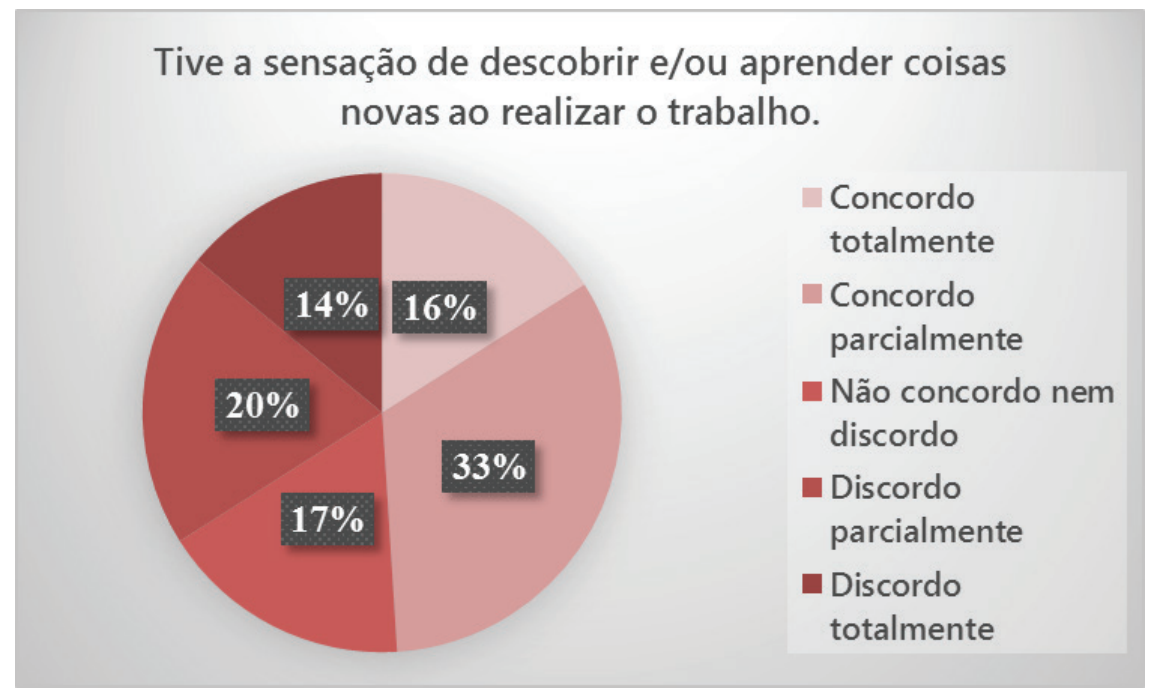

Figura 3 - Os alunos tiveram a sensação de aprender algo novo. 


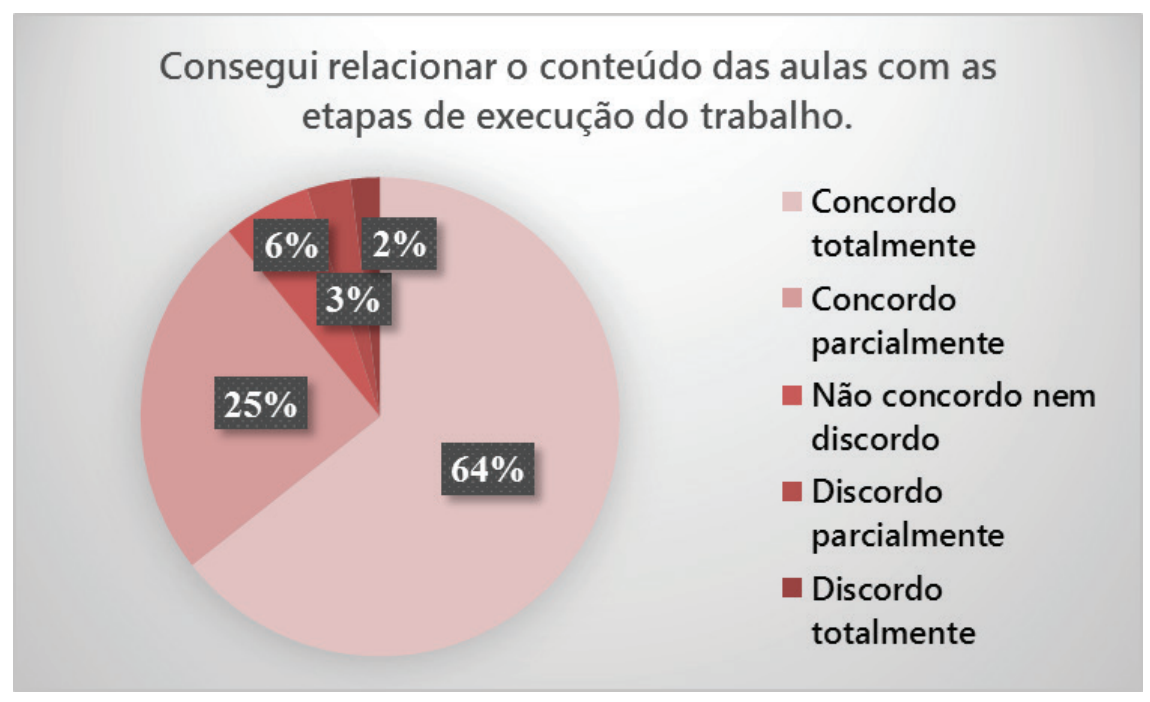

Figura 4 - Foi possível relacionar o conteúdo teórico das aulas com as etapas do trabalho.

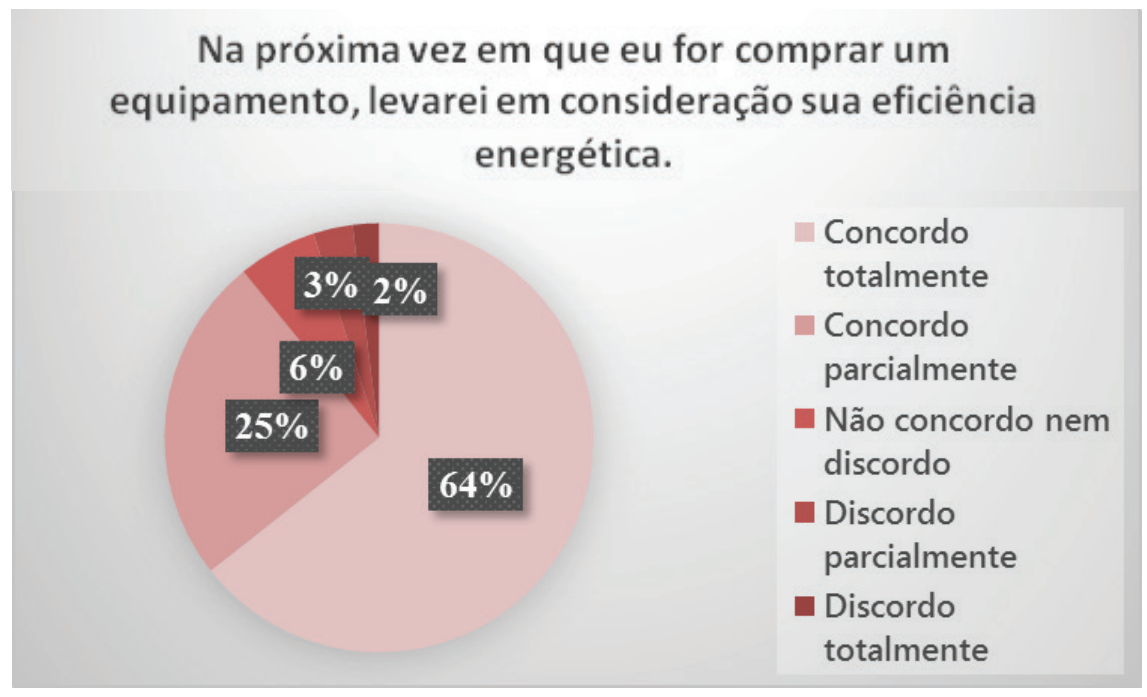

Figura 5 - Os alunos afirmam que vão considerar a eficiência energética dos equipamentos no momento da compra.

universidades, onde será? Observando as respostas livres na seção D do questionário, destacam-se comentários como:

O trabalho fez com que eu obtivesse noção do quanto cada aparelho gasta de energia, sua porcentagem do mesmo no consumo total etc., fazendo com que eu me tornasse mais consciente quanto a isso tanto no âmbito de conhecimentos da área como na questão ambiental e de sustentabilidade.

O trabalho é muito interessante e importante, pois paramos para pensar sobre aspectos de gera- ção de economia de energia fora da sala de aula, mesmo tendo que aproximar e ajustar valores para que sejam condizentes com a realidade.

Assim, o trabalho parece estar cumprindo papel formativo e social no que tange à conscientização sobre os hábitos de consumo dos alunos, futuros engenheiros eletricistas.

Apesar de críticas e sugestões feitas pelos alunos na seção D de opinião livre, também houve muitas manifestações de aceitação e elogios com relação ao trabalho e à disciplina e bons resultados nas questões objetivas nas provas, o que indica que os docentes estão no 
"caminho certo", porém são necessárias modificações e melhorias na disciplina.

Na edição de 2016 e na que se iniciará em 2017, foi introduzida a utilização de um medidor de energia que permite a cada aluno fazer a medição e a análise de dados como a potência e o consumo de energia de cargas especiais, como, por exemplo, geladeiras e máquinas de lavar roupa, já que esses equipamentos têm ciclos de funcionamento especiais. Na turma de 2017, haverá a opção para os alunos montarem e entenderem melhor o princípio de funcionamento do medidor.

\section{Referências Bibliográficas}

BONWELL, G. G. "Active Learning: Creating
Excitement in the Classroom". Active Learning Workshops, 2000. Disponível em: $<$ https://www.ydae.purdue.edu/ lct/HBCU/documents/Active_Learning_Creating Excitement_in_the_Classroom.pdf $>$. Acessado em 13 maio 2014.

LODER, L. L.; NAKAO, O. S. \& FILHO, A. B. C. "Active Learning to Prevent Evasion in Engineering Courses?". Anais: ALE 2014 - Active Learning in Engineering Education Workshop. Caxias do Sul, Universidade de Caxias do Sul, 2014, pp. 171-176.

VILLAS-BOAS, V.; NETO, O. M.; CENSON, A. S. P.; et al. "Aprendizagem Ativa na Educação em Engenharia". In: BAZZO, W. A.; TONINI, A. M.; VILLAS-BOAS, V.; CAMPOS, L. C. \& LODER, L. L. (orgs.). Desafios da Educasãa em Engenharia: Vocação, Formaçãa, Exercício Profissional, Experiências Metodológicas e Proposições. Blumenau: Abenge, Edifurb, 2012, pp. 61-112. 